\title{
Das Verhalten endogener und exogener Jodverbindungen im Serum gegenüber einem basischen Ionenaustauscher ${ }^{1}$ )
}

\author{
Von R. KöDding und H. L. KrüsKemper \\ Abteilung für Klinische Endokrinologie, Dept. Innere Medizin, Medizinische Hocbschule Hannover
}

(Eingegangen am 31. März 1970)

\begin{abstract}
Es wird über die Wirkung von Amberlite IRA-401, einem basischen Ionenaustauscher, auf eine Reihe endogener und exogener Jodverbindungen in Abhängigkeit von der Protein-Konzentration des Serums und der Denaturierung der Serumproteine berichtet. Die Möglichkeiten der Differenzierung verschiedener exogener jodhaltiger Substanzen und der Ermittlung des Hormonjodanteils in einem jodkontaminierten Serum wcrden beschrieben.
\end{abstract}

\section{The reaction of endogenous and exogenous iodine compounds in the serum with a basic ion exchanger}

The action of Amberlite IRA-401, a basic ion exchanger, on a series of endogenous and exogenous iodine compounds and its dependence on the protein concentration of the serum and the denaturation of the serum proteins is described. The possible ways of differentiating between the various exogenous iodine-containing substances and for determining the hormonal iodine in iodine-contaminated serum are described.

Der chemische Jodnachweis im Serum, d.h. die Bestimmung des sog. proteingebundenen Jods (PBI) ist nach wie vor einer der wichtigsten Parameter in der Schilddrüsenfunktions-Diagnostik, nicht zuletzt wegen des vollautomatischen Gangs der Methode (1), der die tägliche Bearbeitung von Großserien gestattet. Leider versagt die PBI-Bestimmung völlig, wenn ein Serum exogenes Jod oder ein pathologisches Jodprotein enthält. Neben der Vielzahl der auf dem Markt befindlichen jodhaltigen Medikamente sind es in erster Linie die jodhaltigen Röntgenkontrastmittel ${ }^{2}$ ), die eine Hormonjod-Bestimmung, oft für mehrere Monate, unmöglich machen (2-8). So erschien es uns zweckmäßig, die Eigenschaften dieser exogenen Jodverbindungen näher zu untersuchen, um sie evtl. unter bestimmten Bedingungen, ohne chromatographische Trennung, vom Hormonjod differenzieren zu können.

Um einen Aufschluß über das unterschiedliche Bindungsvermögen sowohl der endogenen als auch der exogenen Jodverbindungen an die Serumproteine $z u$ erhalten, haben wir die Proteinaffinität dieser Substanzen während einer konkürrierenden Reaktion, nämlich der Einwirkung eines Ionenaustauschers studiert. Durch den Austauscher wird das dynamische Gleichgewicht, das $z$ wischen freier und proteingebundener Substanz besteht, verändert, und es stellt sich ein neues Gleichgewicht zwischen freier, proteingebundener und austauschergebundener Verbindung ein. Vermindert man die Protein-Konzentration, so muß sich nach dem

1) Ein Teil dieser Arbeit wurde auf dem III. Internationalen Kongreß für Endokrinologie, Mexico City, 30.6.-5. 7.1968 vorgetragen.

2) Abkürzungen (vgl. METHODIK: Reagenzien): MJT = Monojodtyrosin, DJT = Dijodtyrosin, $\mathrm{T}_{2}=$ Dijodthyronin, $\mathrm{T}_{3}=\mathrm{Tri}-$ jodthyronin, $\mathrm{T}_{4}=$ Thyroxin, $\mathrm{TGB}=$ Thyreoglobulin; $\mathrm{PBI}=$ proteingebundenes Jod, RKM $=$ Röntgenkontrastmittel.
Massenwirkungsgesetz auch die Konzentration der proteingebundenen Jodverbindung verringern und die am Austauscher adsorbierte Jodmenge erhöhen, damit dieses Gleichgewicht aufrechterbalten wird. Das Ausmaß der Adsorptions-Zunahme kann dabei als Maßstab für die Proteinaffinität der betreffenden Jodverbindung betrachtet werden.

Wir haben die Wirkung einer ganzen Reihe von Ionenaustauschern auf verschiedene endogene und exogene jodhaltige Verbindungen untersucht. Die Intensität der Reaktion auf die einzelnen Jodverbindungen ist bei jedem Austauscher unterschiedlich. Obwohl nicht bekannt ist, wie weit der Vorgang mehr als eine Adsorption oder als ein echter Ionenaustausch anzusehen ist, soll im folgenden jedoch der Einfachheit halber nur von Adsorption gesprochen werden.

In der vorliegenden Arbeit wird das Verhalten der wichtigsten endogenen und exogenen Jodverbindungen im Serum bei verschiedenen Protein-Konzentrationen und bei denaturierten Serumproteinen gegenüber Amberlite IRA-401, einem stark basischen Ionenaustauscher, untersucht. Wir haben diesen Austauscher ausgewählt, weil er bei der routinemäßigen PBI-Bestimmung zur Entfernung des anorganischen Jods verwendet wird und dabei aber auch andere, sowohl physiologische als auch exogene Jodverbindungen in unterschiedlichem $\mathrm{Maße}$ adsorbiert (8). Neben den Jodtyrosinen, Jodthyroninen und Thyreoglobulin ${ }^{2}$ ) als Vertreter eines Jodproteins, wurden die in Tabelle 1 aufgeführten $\mathrm{RKM}^{2}$ ) sowie Vioform, das bisher in seiner jodhaltigen Zusammensetzung noch sehr häufig als Medikament verwendet wurde, näher untersucht. Mit diesen Jodverbindungen werden mehr als $95 \%$ der an unserer Klinik auftretenden Fälle der Jodkontamination eines, Serums exfaßt. Im Verhalten dieser Verbindungen zeigen sich große Unterschiede, so daß es möglich ist, die verschie- 
Tab. 1

Übersicht über die untersuchten exogenen Jodverbindungen (n: Anzahl der Patientenseren)

\begin{tabular}{|c|c|c|c|c|c|c|}
\hline Kurzname & Handelsname & Anion & $\begin{array}{l}\text { Kati } \\
\mathrm{Na}^{+}\end{array}$ & $\begin{array}{l}\text { I\%] } \\
\text { Methyl- } \\
\text { glucamin }\end{array}$ & Anwendung & n \\
\hline $\begin{array}{l}\text { Diatrizoat } \\
\text { (Amidotrizoat) }\end{array}$ & $\begin{array}{l}\text { Urografin } \\
\text { Urovison } \\
\text { Angiografin }\end{array}$ & $\begin{array}{l}\mathrm{N}, \mathrm{N}^{\prime}-\text { Diacetyl-3,5- } \\
\text { diamino-2,4,6-trijodbenzoesäure }\end{array}$ & $\begin{array}{c}13 \\
69 \\
0\end{array}$ & $\begin{array}{r}87 \\
31 \\
100 \\
\end{array}$ & \multirow{2}{*}{ Urographie } & $\begin{array}{l}1 \\
1 \\
2\end{array}$ \\
\hline Iothalamat & Conray 60 & $\begin{array}{l}\text { 5-Acetylamino-2,4,6-trijodisophthalsäure- } \\
\text { methylamid-(3) }\end{array}$ & 0 & 100 & & 0 \\
\hline $\begin{array}{l}\text { Iodipamid } \\
\text { (Adipiodon) }\end{array}$ & Biligrafin & $\begin{array}{l}\text { Adipinsäure-bis-(3-carboxy- } \\
2,4,6 \text {-trijodanilid) }\end{array}$ & 0 & 100 & \multirow{4}{*}{ Cholegraphie } & 5 \\
\hline Iopodat & Biloptin & $\begin{array}{l}\text { 3-(3-Dimethylamino-methylenamino- } \\
\text { 2,4,6-trijodphenyl)-propionsäure }\end{array}$ & 100 & 0 & & 4 \\
\hline $\begin{array}{l}\text { loglycamid } \\
\text { (loglycamat) }\end{array}$ & Bilivistan & $\begin{array}{l}\text { Diglycolsäure-bis-(3-carboxy- } \\
\text { 2,4,6-trijodanilid) }\end{array}$ & 40 & 60 & & 1 \\
\hline Iophenoxinsäure & Teridax & $\begin{array}{l}\text { 3-(3-Hydroxy-2,4,6-trijodphenyl)- } \\
\text { 2-äthylpropionsäure }\end{array}$ & & & & 1 \\
\hline Jodiertes Ol & Lipiodol & $\begin{array}{l}\text { Fettsäureäthylester des jodierten } \\
\text { Oleum Papaveris }\end{array}$ & 一 & 一 & Lymphographie & 6 \\
\hline Jodchlorhydroxychin & Vioform & 5-Jod-7-Chlor-8-hydroxychinolin & - & - & Antiseptikum & 2 \\
\hline
\end{tabular}

denen RKM-Gruppen zu differenzieren und unter bestimmten Voraussetzungen auch den Anteil an Hormonjod in einem kontaminierten Serum zu ermitteln.

\section{Methodik}

\section{Reagenzien}

L-3-Monojodtyrosin, M. A. (Mann Res. Lab., New York)

L-3,5-Dijodtyrosin, p. a. (Serva, Heidelberg)

D, L-3,5-Dijodthyronin (Schuchardt, München)

L-3,5,3'-Trijodthyronin (Diwag, Berlin)

L-Thyroxin, reinst (Serva)

Thyreoglobulin (Schwein), (Mann Res. Lab.)

Urografin 76\%, Urovison, Biligrafin forte (alle Schering A. G., Berlin)

Conray 60, Lipiodol Ultrafluid (beide Byk-Gulden, Konstanz)

Vioform (Ciba A. G., Wehr/Baden)

Amberlite IRA-401, p. a. (Serva)

Human-Trockenplasma (DRK-Blutspendedienst Niedersachsen, Springe)

\section{Herstellung der Lösungen}

a) DJT, $\mathrm{T}_{2}, \mathrm{~T}_{3}, \mathrm{~T}_{4}$ und Vioform wurden in $0,1 \mathrm{~N} \mathrm{NaOH}$ gelöst (Konz.: $1,0 \mathrm{mg} / \mathrm{ml}$ ) und dann mit bidest. Wasser verdünnt. Lipiodol wurde im 1000 fachen Volumen eines Äthanol-AcetonGemisches $(6: 1, \mathrm{v} / \mathrm{v})$ gelöst und mit Wasser weiter verdünnt. Alle übrigen Substanzen wurden in bidest. Wasser gelöst.

b) Aus Trockenplasma-Iösung nativer Konzentration und bidest. Wasser wurden Mischungen verschiedener Protein-Konzentration hergestellt (z. B. Plasma-Konzentration $20 \%$ bedeutet eine 5 fach verdünnte Trockenplasma-Lösung nativer Konzentration, vgl. Abb. 2-4). $\mathrm{Zu}$ je $3,9 \mathrm{~m} /$ dieser Plasmaverdünnungen wurden $0,1 \mathrm{~m} /$ der kontaminierten Seren bzw. der Lösungen der authentischen Jodverbindungen gegeben. Letztere beide wurden vorher soweit mit Wasser verdünnt, daß die Jodkonzentration in der Plasma-Lösung etwa $10 \mu \mathrm{g} / 100 \mathrm{~m} l$ betrug. Nach gründlicher Vermischung blieb die Probe mindestens 5 Min. stehen.

\section{Behandlung mit dem Ionenaustauscher}

Jeweils $2,0 \mathrm{~m} /$ dieser jodhaltigen Plasma-Lösungen wurden mit $200 \pm 5 \mathrm{mg}$ Amberlite IRA-401 (in der feuchten Handelsform; Wassergehalt $47,6 \%$ ) in einem Reagenzglas 5 Min. geschüttelt und in einen Probenbecher des AutoAnalyzers filtriert. Auf die gleiche Weise wurde mit jodkontaminierten Seren direkt oder mit Wasser verdünnt (ohne Vermischung mit Trockenplasma'-Lösung) verfahren. In diesen Fällen wurde nach der Behandlung mit dem Austauscher (vor der Jodmessung) mit Wasser auf eine Jodkonzentration von etwa $10 \mu \mathrm{g} / 100 \mathrm{~m} /$ verdünnt.

\section{Alkali-Behandlung des Serums}

$2,0 \mathrm{~m} /$ Serum, allein oder im Gemisch mit Trockenplasma-Lösung, wurden mit $0,05 \mathrm{~m} / 32$ proz. Natronlauge versetzt. Nach gründlicher Durchmischung und einer Reaktionsdauer von $6 \mathrm{Min}$. bei $20^{\circ}$ wurde mit dem Austauscher geschüttelt.

\section{Jodbestimmung}

Die Messung der Jodkonzentration wurde nach J. und N. BENOTrI (1) mit einem AutoAnalyzer (Technicon GmbH, Frankfurt/M.) durchgeführt (Prinzip: Katalyse der Reduktion von CerIV durch Arsenit). Von den $4,0 \mathrm{ml}$ der wie oben beschrieben hergestellten Jodlösungen wurde die Jodkonzentration in der einen Hälfte nach Behandlung mit dem Austauscher, in der anderen Hälfte ohne dieselbe direkt gemessen. Die Adsorption berechnete sich aus den beiden gemessenen Jodkonzentrationen (bzw. den Gipfelhöhen) unter Berücksichtigung des $T_{4}$-Gehaltes der Trockenplasma-Lösung (meistens 2 bis $3 \mu \mathrm{g} / 100 \mathrm{ml}$ in nativer Konz.). Seren, die zuvor mit Alkali behandelt worden waren, unterwarfen wir gleich nach Filtration der Jodbestimmung, um einer Gelierung zuvorzukommen. Ließ sich die Gelierung dennoch nicht vermeiden, so konnte durch Rühren mit einem zur Spitze ausgezogenen Glasstab oder einer Pasteur-Pipette dem Serum Festsubstanz entzogen werden, wobei es wieder flüssig wurde und die Jodkonzentration sich nicht merklich änderte.

\section{Ergebnisse}

\section{Abhängigkeit der Adsorption von der Protein-} Konzentration

\section{Endogene Jodverbindungen}

Von den Jodtyrosinen (MJT und DJT) werden aus unverdünntem Plasma jeweils 30 bis $35 \%$ durch Amberlite IRA-401 adsorbiert (Abb. 1). Unter den gleichen Bedingungen beträgt die Adsorption von $T_{2}$ und $T_{3}$ 52 bzw. 46\%. Bei allen vier Verbindungen nimmt die Adsorption mit steigender Plasmaverdünnung fast linear zu und erreicht - außer bei MJT - 100\% bei unendlicher, also praktisch etwa 500- bis 1000 facher Verdünnung; d. h. aus wäßriger, proteinfreier Lösung werden DJT, $T_{2}$ und $T_{3}$ vollständig adsorbiert. Bei MJT hingegen existiert ein Adsorptionsmaximum bei 20 facher Plasmaverdünnung. Bei niedrigerer Protein-Konzentration fällt die Adsorption wieder ab, was möglicherweise 


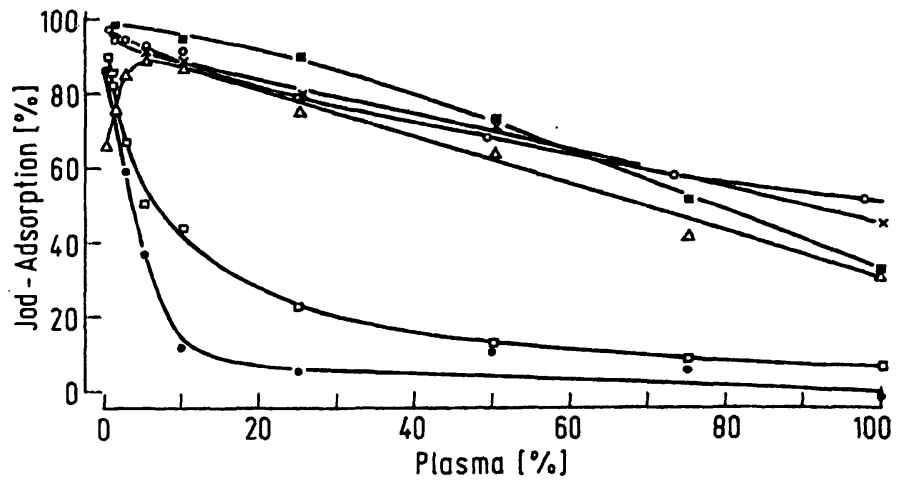

Abb. 1

Einfluß der Plasmaverdünnung auf die Adsorption von Monojodtyro$\sin (M J T \Delta)$, Dijodtyrosin (DJT $\omega)$, Dijodthyronin ( $T_{2}$ o), Trijodthyronin $\left(\mathrm{T}_{3}, X\right)$, Thyroxin $\left(\mathrm{T}_{4} \mathrm{D}_{\text {Amberlite IRA-401 }}\right.$ und Thyreoglobulin (TGB $\bullet$ ) an

auf eine besondere Stabilisierung der Verbindung in diesem Konzentrationsbereich zurückzuführen ist.

Anders ist das Verhalten von $\mathrm{T}_{4}$ und TGB. Bei beiden Verbindungen ist die Adsorption an Amberlite im unverdünnten Plasma nur gering ( $7 \mathrm{bzw} .0 \%$ ). Mit fortschreitender Verdünnung nimmt sie anfangs nur allmählich zu und steigt erst bei starker Verdünnung steil an; sie erreicht aber nur 90 bzw. 86\% in wäßriger Lösung. Die Ähnlichkeit im Verhalten von $\mathrm{T}_{4}$ verglichen mit TGB zeigt deutlich den Einfluß der starken Affinität dieser Verbindung zu Serumprotein, wenn man bedenkt, daß die chemische Bindung des Jods im TGB kovalent ist.

\section{Exogene Jodverbindungen}

Von den RKM zur Urographie (Diatrizoat in Form von Urovison, Urografin und Angiografin sowie Iothalamat als Conray) werden 43\% durch Amberlite IRA 401 aus unverdünntem Plasma adsorbiert (Abb. 2). Mit abnehmender Protein-Konzentration steigt die Adsorption in etwa linear an und erreicht $100 \%$ bei extrem starker Verdünnung.

Bei den RKM zur Cholegraphie (Iodipamid als Biligrafin, Iopodat als Biloptin, Ioglycamid als Bilivistan und Tophenoxinsäure als Teridax) hingegen ist die Adsorption im unverdünnten Plasma nur gering ( $<20 \%)$. Sie bleibt auch bei fortschreitender Verdünnung konstant und steigt erst bei sehr niedriger Protein-Konzen-

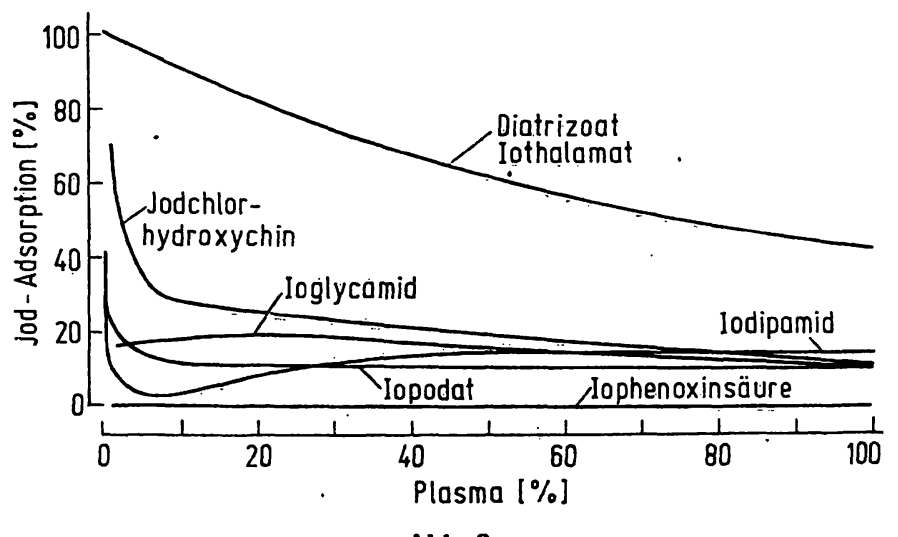

Abb. 2

Einfluß der Plasmaverdünnung auf die Adsorption einiger exogener Jodverbindungen an Amberlite IRA-401 tration steil an. Bei Iodipamid besteht ein AdsorptionsMinimum zwischen einer Plasma-Konzentration von 5 und $10 \%$. Offenbar liegt in diesem Konzentrationsbereich eine intensive Stabilisierung dieser Verbindung vor. Die äußerst stark ausgeprägte Proteinbindung von Teridax, Ursache der sich über Jahrzehnte hinziehenden Elimination dieser Verbindung aus dem menschlichen Organismus, zeigt sich deutlich in dem Verhalten gegenüber dem Ionenaustauscher. Bis herunter zu mindestens 100 facher Plasmaverdünnung ist die Adsorption praktisch gleich Null.

Jodchlorhydroxychin als Vioform nimmt in seiner Affinität zu den Plasmaproteinen eine Mittelstellung zwischen den RKM zur Urographie und Cholegraphie ein. Die Adsorption steigt von $11 \%$ in unverdünntem Plasma mit der Verdünnung zunächst nur leicht, oberhalb 10 facher Verdünnung jedoch steil an.

Die meisten der genannten exogenen Jodverbindungen wurden im Serum mehrerer Patienten ( $n: 1-6 ; s$. Tab. 1) untersucht. Der Kurvenverlauf bei den Patienten untereinander stimmt innerhalb jeder Substanzgruppe gut überein. Die angegebenen Kurven geben einen mittleren Verlauf wieder. Auf Angabe einzelner Meßpunkte wurde einer besseren Übersichtlichkeit wegen verzichtet. $\mathrm{Ob}$ ein Serum direkt oder nach Vermischung mit Trockenplasma-Lösung dem Ionenaustauscher ausgesetzt wurde, hatte auf die Adsorptionsquote keinen Einfluß. Die gleichen Versuche wurden durch Zusatz von authentischen Präparaten dieser Jodverbindungen zu Trockenplasma-Lösung verschiedener Konzentration durchgeführt. Bei den RKM zur Urographie und Cholegraphie zeigten sich dabei die gleichen Kurvenverläufe wie bei den entsprechenden Patienten-Seren, lediglich mit einer geringen Verschiebung in den Bereich niedrigerer Adsorption, was auf eine etwas stärkere Proteinbindung der Substanzen im Nativserum schließen läßt. Iothalamat wurde nur durch diesen in vitro-Versuch getestet. Sein Verhalten war mit dem von Diatrizoat identisch.

Im Gegensatz dazu ist die Jodadsorption an Amberlite in Seren nach Lymphographie mit Lipiodol bei den einzelnen Patienten unterschiedlich stark (Abb. 3). Sie

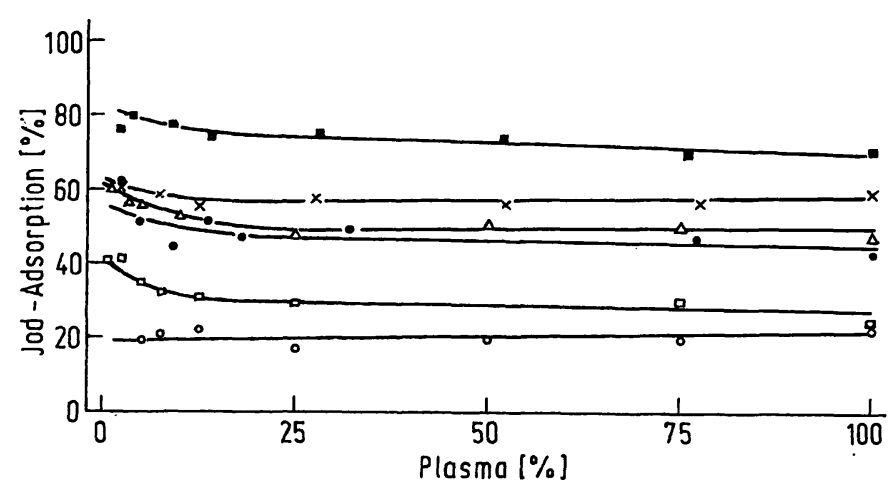

Abb. 3

Einfluß der Plasmaverdünnung auf die Adsorption von Lipiodol-Jod an Amberlite IRA-401 bei verschiedenen Patienten und unterschied-

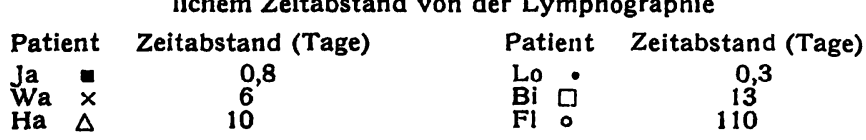


schwankt bei den untersuchten, unverdünnten Seren zwischen 20 und $70 \%$. Bei allen Seren jedoch bleibt die Adsorption bis zu etwa 5 facher Verdünnung konstant und steigt bei weiterer Verdünnung leicht an. Die Stärke der Adsorption scheint mit dem Alter des Lipiodols im Körper zusammenzuhängen. Je länger die Lymphographie zurückliegt, desto geringer ist die Adsorption an den Austauscher, was auf eine mit der Zeit zunehmende Bindung des Lipiodol-Jods im Organismus schließen läßt.

\section{Jodadsorption nach Alkali-Behandlung des Serums}

Inkubiert man das unverdünnte Serum vor der Anwendung des Ionenaustauschers in alkalischem Milieu ( $\mathrm{NaOH}-\mathrm{Konz} .: 1 \% ; 6 \mathrm{Min} ., 20^{\circ}$ ), so erhöht sich die Adsorption bei fast allen genannten Jodverbindungen beträchtlich gegenüber der Adsorption aus Neutralserum (Abb. 4). Lediglich bei Lipiodol nimmt die Jodadsorption nur geringfügig zu, während Thyreoglobulin auch aus alkalischem Serum nicht adsorbiert wird. Die geringe Adsorptionserhöhung durch die Alkali-Einwirkung gilt bei Lipiodol sowohl für die Seren mit starker als auch für die mit schwacher Adsorption aus Neutralserum (Abb. 3). Ein Fall mittelstarker Adsorption ist in Abbildung 4 dargestellt. Offensichtlich werden die Serumproteine durch die Einwirkung von Alkali denaturiert, so daß die Bindungsmöglichkeit der jodhaltigen Substanzen erheblich herabgesetzt ist und die Affinität dieser Verbindungen zum Ionenaustauscher überwiegt.

Aus dem Verhalten des Lipiodol-Jods kann man schlieBen, daß es zu einem bestimmten Anteil, der mit der Verweildauer im Organismus zunimmt, nicht mehr als Lipiodol vorliegt und extrem stark, wahrscheinlich durch Kovalenz, an Serumprotein gebunden ist. Das würde mit den Untersuchungen von J. Mantzos und Mitarbeitern (9) im Einklang stehen, die nach Lymphographie mit Lipiodol im Hydrolysat des Serumalbumins MJT dünnschichtchromatographisch nachgewiesen haben.

Bemerkenswert ist nòch die auffällig niedrige Adsorption von Iopodat in alkalischem Serum verglichen mit der der anderen RKM zur Cholegraphie. Die stärkere Proteinbindung, die daraus spricht, wird durch den Zeitraum der Ausscheidung aus dem Orgànismus bestätigt, der bei oralen Gallenkontrastmitteln erheblich gröBer ist, als bei den übrigen Kontrastmitteln zur Cholegraphie (3).

Unsere Untersuchungen bestätigen also, daß die RKM zur Urographie nur geringe Affinität zu den Serumproteinen besitzen, während dieselben zur Chole- und Lymphographie stark eiweißgèbunden sind (10-13).

Anhand ihres Verhaltens gegenüber Amberlite IRA-401 in neutralem (unverdünntem und verdünntem) und alkalischem Serum lassen sich die drei Gruppen von RKM durch einen einfachen Adsorptionstest differenzieren. Man behandelt unverdünntes, $10 \mathrm{fach}$ verdünntes und alkalisches Serum mit dem Ionenaustauscher. Wird aus alkalischem Serum nur wenig mehr adsorbiert als aus Neutralserum, so liegt Lipiodol vor. Beträgt die Adsorption sowohl in unverdünntem als auch in verdünntem Serum weniger als $20 \%$, handelt es șich um ein Gallenkontrastmittel. Von einem Kontrastmittel zur Urographie schließlich wird in unverdünntem Serum fast die Hälfte und nach 10 facher Verdünnung $90 \%$ adsorbiert.

\section{Diskussion}

Die Ausscheidung aus dem Organismus verläuft bei den einzelnen exogenen Jodverbindungen mit sehr unterschiedlicher Geschwindigkeit, und so ergeben sich Zeit-
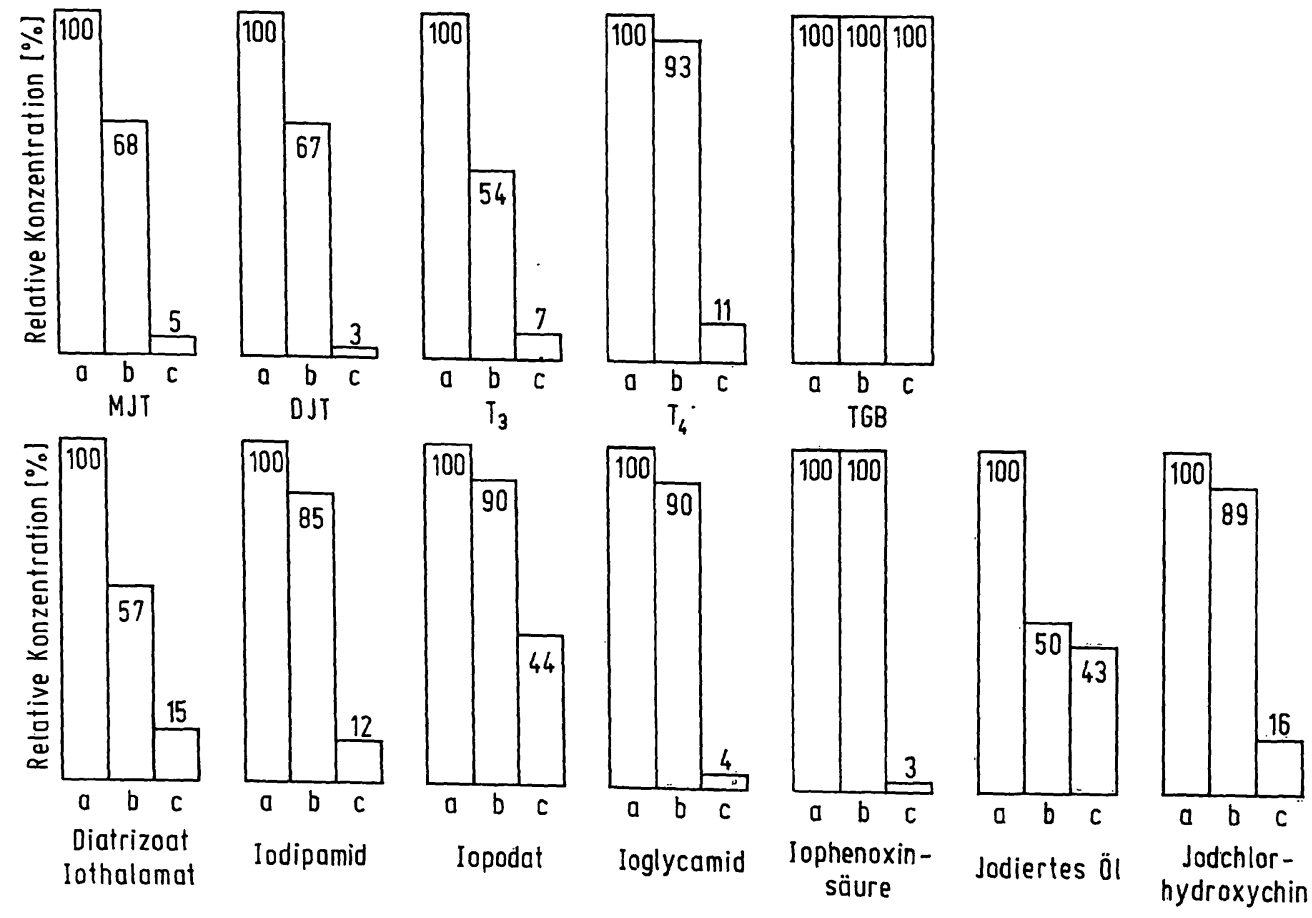

Abb. 4

Relative Konzentrationen (\%) einiger endogener und exogener Jodverbindungen im Serum vor (a) und nach $(b, c)$ Behandlung mit Amberlite IRA-401; (a), (b): Neutralserum; (c): alkalisches Serum

Iothalamat

säure

Z. klin. Chem. u. klin. Biochem. / 8. Jahrg. 1970/ Heft 4 
spannen von einigen Tagen bis zu einigen Jahren, in denen die Hormonjodbestimmung in einem kontaminierten Serum ohne chromatographische Trennung nicht möglich ist. $\mathrm{Da}$ diese Ausscheidungsraten für die RKM bekannt sind $(2-5,7)$, ließe sich der Zeitpunkt einer einwandfreien PBI-Bestimmung absehen, wenn man weiß, welches Kontrastmittel im Serum vorliegt. In vielen Fällen ist dies jedoch durch Anamnese nicht in Erfahrung zu bringen, so daß ein einfacher Test, wie der beschriebene, von großem Nutzen sein kann.

Ist das Vorliegen eines RKM zur Urographie gesichert, so ist der einfachste Weg, der in den meisten Fällen auch gangbar ist, die PBI-Bestimmung nach ein paar Tagen zu wiederholen, denn diese Gruppe von RKM wird relativ schnell aus dem Organismus eliminiert. Bei den anderen beiden Gruppen dagegen bleibt der Jodspiegel des Serums mindestens 1-2 Monate erhöht.

Durch das Verhalten gegenüber Amberlite IRA-401 läßt sich aber nicht nur das Kontrastmittel feststellen, sondern auch in vielen Fällen geringerer Jodkontamination (Gesamtjod-Konzentration des Serums < etwa $50 \mu \mathrm{g} / 100 \mathrm{ml})$ das Verhältnis von exogenem zu endogenem Jod abschätzen oder gar ermitteln. Von den endogenen Jodverbindungen sind - durch die Nachweisempfindlichkeit ihrer Jodkonzentration bedingt nur $T_{4}$ und TGB zu berücksichtigen. Wenn also der PBI-Wert eines Serums höher ist, als nach der klinischen Diagnose zu erwarten wäre, so gilt es, den Anteil von $\mathrm{T}_{4}$ gegenüber allen anderen genannten Jodverbindungen, den exogenen und auch TGB, als pathologischem Jodprotein, mengenmäßig abzuschätzen. Das läßt sich am besten nach dem unten beschriebenen Schema durchführen. Man teilt die Seren nach der Höhe der Jodadsorption im unverdünnten Neutralserum in drei Gruppen ein: $<20 \%, 20-50 \%$ und $>50 \%$ und überlegt, welche Verbindungen jeweils neben $\mathrm{T}_{4}$ anwesend sein können und welche auszuschließen sind. Als weitere Einschränkung dient dann die Adsorption in alkalischem Serum und in verdünntem Neutralserum.

Adsorption in Neutralserum $<20 \%$

Anwesenheit möglich: TGB, RKM zur Cholegraphie (RKM-Ch), Vioform.

Anwesenheit ausgeschlossen: RKM zur Utographie (RKM-U) und Lymphographie (RKM-L).

a) Adsorption in alkalischem Serum $<80 \%$ : RKM-Ch und Vioform sind auszuschließen. Die Anwesenheit von TGB ist sicher (bei $56-80 \%$ auch Iopodat möglich). Der prozentuale Anteil an TGB ist umgekehrt proportional der Adsorption und kann rechnerisch oder graphisch ermittelt werden (lineare Abhängigkeit; $0 \%$ TGB $=100 \% \mathrm{~T}_{4}$ : Adsorption $89 \% ; 100 \% \mathrm{TGB}=0 \%$ $\mathrm{T}_{4}$ : Adsorption $0 \%$ ).

b) Adsorption in alkalischem Serum $>80 \%$ : TGB ist auszuschließen. Die Anwesenheit von RKM-Ch oder Vioform ist möglich. Beide Verbindungen lassen sich aber weder untereinander noch von $\mathrm{T}_{4}$ auf einfache Weise differenzieren. In manchen Fällen wird sich jedoch der $\mathrm{T}_{4}$-Anteil durch die Adsorptionszunahme in 10- bis $20 \mathrm{fach}$ verdünntem Serum gegenüber unverdünntem Serum abschätzen lassen. Diese Zunahme ist bei reinem $\mathrm{T}_{4}$ sehr groß, bei Vioform mäßig und bei reinem RKM$\mathrm{Ch}$ praktisch gleich Null.

\section{Adsorption in Neutralserum 20 bis $50 \%$}

Anwesenheit möglich: RKM-U, RKM-L.

Anwesenheit ausgeschlossen: TGB, RKM-Ch, Vioform.

a) Adsorption in alkalischem Serum $>85 \%$ : RKM-L ist auszuschließen. Die Anwesenheit von RKM-U ist sicher. Das Mengenverhältnis von $T_{4}$ zu RKM-U kann man rechnerisch oder graphisch aus der Adsorption im unverdünnten Neutralserum ermitteln $(0 \%$ RKM-U = $100 \% \mathrm{~T}_{4}$ : Adsorption $7 \% ; 100 \%$ RKM-U $=0 \% \mathrm{~T}_{4}$ : Adsorption 43\%). Ein weiterer Nachweis von RKM-U kann durch Adsorption in verdünntem Serum erfolgen: Je mehr der Anstieg der Adsorption mit der Verdünnung linear zunimmt, desto größer ist der Anteil an RKM-U.

b) Adsorption in alkalischem Serum < 85\%: RKM-U ist auszuschließen. Die Anwesenheit von RKM-L ist sicher. Der Anteil von RKM-L ist um so größer, je geringer die Adsorptions-Differenz zwischen neutralem und alkalischem Serum ist (siehe unten).

\section{Adsorption in Neutralserum 50 bis $70 \%$}

Anwesenheit möglich: RKM-L.

Anwesenheit auszuschließen: TGB, RKM-U, RKM-Ch, Vioform.

Je stärker die Adsorptions-Zunahme in alkalischem Serum gegenüber Neutralserum ist, desto geringer ist der Anteil an RKM-L. Weiterer Nachweis von RKM-L: Die Adsorption ist bis herunter zu etwa 5 facher Verdünnung des Serums konstant. Dieser Effekt ist um so stärker ausgeprägt, je größer der prozentuale Anteil von RKM-L ist.

Das Verfahren der Adsorption an Amberlite IRA-401 kann nicht dazu benutzt werden, um exogenes Jod durch wiederholtes Ausschütteln mit jeweils frischem Austauscher quantitativ aus dem Serum zu entfernen und das zurückbleibende $\mathrm{T}_{4}$ als $\mathrm{PBI}$ zu messen. Wegen des zu großen Überschusses des exogenen Jods gegenüber dem Hormonjod und der relativ geringen Adsorptionsquote der störenden Jodverbindungen (max. $43 \%$ bei RKM zur Urographie) wären zu viele Adsorptionsschritte notwendig, wobei jedesmal auch 5-10\% $\mathrm{T}_{4}$ adsorbiert würden. Ferner entzieht der Austauscher in seiner Handelsform (feuchtes Granulat) dem Serum Wasser, so daß bei sukzessivem Arbeiten das Serum stark viskos wird und nicht mehr filtrierbar ist. Durch den Wasserentzug tritt außerdem eine Erhöhung der Jodkonzentration ein, so daß eine geringere Jodadsorption vorgetäuscht wird. Selbst durch ein vorangehendes Quellen des Austauschers in Wasser würde sich eine unkontrollierbare Veränderung der Jodkonzentration nicht vermeiden lassen. 
Zum Schluß sei noch auf einen allgemeinen Gesichtspunkt hingewiesen, der für die Praxis von Bedeutung ist. Aus den geschilderten Untersuchungen geht hervor, $\mathrm{da} ß$ die routinemäßige Bestimmung des sog. PBI, d. h. die chemische Bestimmung des Jodgehaltes eines Serums nach Behandlung mit einem Ionenaustauscher zwecks Entfernung des anorganischen Jods, nicht zweckmäßig ist. Es sind im wesentlichen drei Gründe, die dafür sprechen, grundsätzlich den Gesamtjodwert zu messen und den Jodidanteil $(0,1-0,3 \mu \mathrm{g} / 100 \mathrm{~m} /)$, der ja praktisch eine sehr geringe physiologische Streuung besitzt, rein rechnerisch zu berücksichtigen, und zwar als Mittelwert $0,2 \mu \mathrm{g} / 100 \mathrm{ml}$. Der Fehler, den man generell dabei begeht, kann dann maximal $0,1 \mu \mathrm{g} / 100 \mathrm{~m} l$ betragen, was innerhalb der Fehlerbreite der Methode liegt und für die klinische Beurteilung ohnehin nicht von Bedeutung wäre. Der erste Grund ist die Tatsache, $\mathrm{da} ß$ zu niedrige PBI-Werte ermittelt werden, weil neben dem Jodid etwa die Hälfte des $\mathrm{T}_{3}$ und etwa $5-10 \%$ des $\mathrm{T}_{4}$ (bei hohen $\mathrm{T}_{4}$-Werten oder erniedrigtem Thyroxin-bindendem Globulin wahrscheinlich noch mehr) an den Ionenaustauscher Amberlite IRA-401 adsorbiert werden. Zweitens werden exogene Jodverbindungen in unkontrolliertem Ausmaß ebenfalls adsorbiert, so daß sich bei relativ niedrigem exogenem Jodanteil der Unterschied zwischen dem effektiv gemessenen und dem echten, dem klinischen Bild entsprechenden PBIWert, verringert und ein exogener Jodanteil eher übersehen wird. Der dritte Grund schließlich ist die erhebliche Arbeitserleichterung, die besonders bei großen, ständig wiederkehrenden Serien ins Gewichț fällt.

Die Arbeit wurde mit technischer Assistenz von Frau K. KuHL und Frau I. LEHwald durchgeführt.

\section{Literatur}

1. Benottr, J. und N. Benottr, Clin. Chem. (New York) 9, 408 (1963). - 2. Frischauf, H., N. Honetz, H. Jesserer, R. KotzauReK und N. Steffenelli, Dtsch. Arch. klin. Med. 207, 329 (1961). -3. Foldenauner, A., Ch. Meynen und P. Böhm, Dtsch. med. Wschr. 92, 745 (1967). - 4. WIENER, J. D. und E. T. BACKER, Clin. chim. Acta (Amsterdam) 20, 155 (1968). - 5. Aquaron, R., Marseille méd. 106, 1 (1969). - 6. JonEs, J. E. und J. S. ShuLtz, J. Clin. Endocr., Springfield 27, 877 (1967). - 7. KRÜSKEMPER, H. L., K. D. Morgner und F. ZIELSKe, diese Z. 7, 28 (1969). -

8. KöDdrNg, R. und H. L. Krüskemper, Klin. Wschr. 46, 143
(1968). - 9. Mantzos, J., L. Chiotaki, G. Rigopoulos, P. D. Papapetrou, S. N. Papadopoulos, D. A. Koutras und B. MalaMos, 3rd Annual Meeting of the European Thyroid Association, Athen (1969). - 10. Bennhold, H., H. Otr und M. WIECH, Dtsch. med. Wschr. 75, 11 (1950). - 11. Lasser, E. C., R. S. FarR, T. Fujimagari und W. N. Tripp, Amer. J. Roentgenol., 87, 338 (1962). - 12. OEfF, K., Naunyn-Schmiedebergs Arch. exp. Pathol. Pharmakol. 222, 523 (1954). - 13. Lajos, I., Fortschr. Gebiete Röntgenstrahlen 85, 292 (1956).

Dr. R. Ködding; Prof. Dr. H. L. Krüskemper Medizinische Hochschule Hannover D 3000 Hannover Podbielskistr. 380 